\title{
Component analysis of Pu-erh and its anti-constipation effects
}

\author{
GUIJIE LI* ${ }^{*}$, QIANG WANG ${ }^{*}$, YU QIAN, YALIN ZHOU, RUI WANG and XIN ZHAO \\ Department of Biological and Chemical Engineering, Chongqing University of Education, \\ Chongqing 400067, P.R. China
}

Received June 21, 2013; Accepted February 19, 2014

DOI: $10.3892 / \mathrm{mmr} .2014 .2009$

\begin{abstract}
The aim of this study was to investigate the effects of Pu-erh tea on activated carbon-induced constipation in ICR mice. The changes in body weight, dietary intake, gastrointestinal transit, first black stool defecation time, number and weight of feces, water content of feces and various levels of substances in serum were used to evaluate the anti-constipation effects of Pu-erh tea. Body weight, dietary intake and the amount of water consumed by mice decreased with activated carbon-induced constipation and those of the sample treated group mice were higher than the control group mice. The first black stool time of normal, control, bisacodyl (100 mg/kg) and 200, 400 and $800 \mathrm{mg} / \mathrm{kg}$ Pu-erh tea treated mice were 90, 221, 118, 178, 155 and $139 \mathrm{~min}$, respectively. Following oral administration of 200,400 and $800 \mathrm{mg} / \mathrm{kg}$ of $\mathrm{Pu}$-erh tea and $100 \mathrm{mg} / \mathrm{kg}$ of bisacodyl, the gastrointestinal transit rates were shortened by 48.6, 59.6, 78.0 and $91.9 \%$, respectively. Serum levels of motilin (MTL), gastrin (Gas), endothelin (ET), acetylcholine enzyme (AchE), substance $\mathrm{P}$ (SP) and vasoactive intestinal peptide (VIP) were significantly increased and somatostatin (SS) was decreased when the mice were treated with different concentrations of $\mathrm{Pu}$-erh tea compared with the untreated control mice. These results demonstrate that $\mathrm{Pu}$-erh tea has a similar preventive effect to bisacodyl and it may be used as a functional food to prevent constipation.
\end{abstract}

\section{Introduction}

Tea is known for its laxative effects and may be found in a variety of dietary supplements, weight loss teas and colon cleaning preparations (1). In general, tea is used as a drink, food or medicine. Tea has been recognized in different

Correspondence to: Professor Xin Zhao, Department of Biological and Chemical Engineering, Chongqing University of Education, 9 Xuefu Main Street, Nan'an, Chongqing 400067, P.R. China

E-mail: foods@live.cn

*Contributed equally

Key words: Pu-erh tea, activated carbon, constipation, bisacodyl, gastrointestinal transit systems of traditional medicine for the treatment of different diseases and ailments, however there are a few studies available on the clinical uses of herbs as constipation treatments that have demonstrated promising results, particularly $\mathrm{Pu}$-erh tea. Pu-erh tea is commonly known as the large leaves of C. sinensis O. kuntze var. assamica Kitamura, a plant native to China (2). Drinking Pu-erh tea for a long period of time is able to aid the maintenance of mental and physical health. This tea is believed to reduce high blood pressure and cholesterol levels, and to be important in preventing heart disease and cancer (3). However, the preventive effect of Pu-erh tea on activated carboninduced constipation in mice has not been clearly studied.

Constipation is medically defined as fewer than three stools per week and severe constipation as less than one stool per week. Constipation occurs when the colon absorbs too much water (4). In the present study, mice were orally administered activated carbon, which attached to the gastrointestinal mucosal surfaces and reduced the drainage of the gastrointestinal tract, reduced gastrointestinal fluid and slowed down gastrointestinal movement, and above all resulted in weakness of the spleen and the stomach, thereby establishing a model of constipation.

In previous studies, constipation induced by activated carbon was used to demonstrate the effects of drugs for the treatment of constipation $(5,6)$. A large number of studies also demonstrated that a megadose of activated carbon is able to induce digestive tract obstruction (7). Therefore, in the present study, we examined the functional effects of Pu-erh tea in the enteron alimentary tract by adopting the activated carboninduced constipation mice model to provide insights into to the inhibitory effect of Pu-erh tea using various concentrations. We examined body weight, dietary intake, drinking water amount, gastrointestinal transit, first black stool defecation time and used a serum assay to measure motilin (MTL), gastrin (Gas), endothelin (ET), somatostatin (SS), acetylcholine enzyme (AchE), substance P (SP) and vasoactive intestinal peptide (VIP) levels. In the present study, we used bisacodyl, a laxative drug that is able to stimulate intestinal peristalsis by working directly on the colon to produce a bowel movement, as a positive control. It is typically prescribed for the relief of constipation and for the management of neurogenic bowel dysfunction as well as part of bowel preparation prior to medical examinations $(8,9)$.

\section{Materials and methods}

Preparations of Pu-erh tea. Seven-son tea cake Pu-erh tea was purchased from Menghai County Yunhai Tea Factory (Yunan, 
China). The Pu-erh tea was stored at $-80^{\circ} \mathrm{C}$ and freeze-dried to produce a powder. A 20 -fold volume of boiling water was added to the powdered sample and extracted twice. The water extract was evaporated using a rotary evaporator (N-1100; Eyela-Tokyo Rikakikai Co., Ltd., Tokyo, Japan), concentrated and then dissolved in dimethylsulfoxide (DMSO; Amresco, Solon, $\mathrm{OH}$, USA) to adjust to the stock concentration $(20 \%, \mathrm{w} / \mathrm{v})$.

Liquid chromatography-mass spectrometry (LC-MS) analysis. The tea extracts were dissolved in DMSO to produce a final concentration of $10 \mathrm{mg} / \mathrm{ml}$ and then diluted with $50 \%$ methanol to make a final concentration of $2 \mathrm{mg} / \mathrm{ml}$. The diluted sample (5 $\mu$ l) was analyzed by liquid chromatography followed by tandem mass spectrometry (LC-MS/MS). LC-MS/MS was performed using a Finnigan LCQ Advantage MAX ion trap mass spectrometer (Thermo Electron Co., Waltham, MA, USA) equipped with an electrospray ionization source. Separation by HPLC was performed with a Finnigan Surveyor Modular HPLC System (Thermo Electron Co.) using an Xterra MS C18 column (5 $\mu \mathrm{m}, 2.1 \times 150$ mm; Waters Corp., Dublin, Ireland). Mobile phase A was water and mobile phase B was acetonitrile; the two contained $0.1 \%$ formic acid. Gradient elution at a flow rate of $0.2 \mathrm{ml} / \mathrm{min}$ was performed as follows: $0-5 \mathrm{~min}$ with $0-40 \%$ B (linear gradient), 5-20 min with 40-80\% B (linear gradient), $20-25$ min with $80-100 \%$ B (linear gradient) and 25-30 min with $100 \%$ B (isocratic). Full-scan mass spectra were obtained in the positive and negative ion modes at a range of $\mathrm{m} / \mathrm{z}$ 100-1,000. For identifying compound structures, data obtained from the MS/MS analysis were compared with that from an MS/MS spectral library search (10).

Animals. This study followed a protocol approved by the Animal Ethics Committee of Chongqing Medical University (Chongqing, China). Seven-week-old female ICR mice $(n=120)$ were purchased from the Experimental Animal Center of Chongqing Medical University. They were maintained in a temperature controlled (temperature, $25 \pm 2{ }^{\circ} \mathrm{C}$; relative humidity, $50 \pm 5 \%$ ) facility with a $12 \mathrm{~h}$ light/dark cycle and free access to a standard rat chow diet and water.

Induction of constipation in mice. To investigate the preventive effects of $\mathrm{Pu}$-erh tea against activated carbon-induced constipation, the animals were divided into 6 groups of 10 mice each. The experimental design was as follows: the normal group was administered arabic gum water for 9 days and a single dose of vehicle treatment $(0.2 \mathrm{ml}$ of $10 \%$ arabic gum, w/w). The activated carbon control group received oral administration of activated carbon $(0.2 \mathrm{ml}$ of $10 \%$ activated carbon, w/w; activated carbon dissolved in $10 \%$ arabic gum) at 6:00 p.m. from the sixth to ninth day to induce constipation. The sample and activated carbon groups were orally administered a dose of 200, 400 and $800 \mathrm{mg} / \mathrm{kg}$ body weight of $\mathrm{Pu}$-erh tea extract and $100 \mathrm{mg} / \mathrm{kg}$ body weight of bisacodyl dissolved in water at 10:00 a.m. everyday for 9 days and constipation was induced as mentioned. The body weight, diet intake, water intake, stool weight and stool moisture were determined at 9:00 a.m. everyday.

Gastrointestinal transit and defecation time. Mice fasted for $16 \mathrm{~h}$ from the ninth day at 6:00 a.m., but were not deprived of water. Following $16 \mathrm{~h}$, the mice from the control and sample groups received oral administration of $10 \%$ activated carbon and the mice in the normal group were administered $10 \%$ arabic gum. After $30 \mathrm{~min}$, mice were sacrificed by cervical dislocation under anesthesia with diethyl ether. The 10 mice from each group were dissected and the small intestine from the pylorus to the blind intestine was carefully removed. The gastrointestinal transit of each mouse was calculated as the percentage of the distance traveled by the activated carbon meal relative to the total length of the small intestine. The equation was used to calculate GI transit (\%): GI transit $(\%)=($ distance traveled by the activated carbon)/(total length of the small intestine) $\mathrm{x} 100$. The last 10 mice of each group were used to determine the first black stool time following $10 \%$ oral administration with activated carbon.

MTL, Gas, ET, SS, AchE, SP and VIP levels in serum. MTL, Gas, ET, SS, AchE, SP and VIP levels in the serum were determined using radioimmunoassay kits (Beijing Puer Weiye Biotechnology Co., Ltd., Beijing, China).

Statistical analysis. Data are presented as the mean \pm SD. Differences between the mean values for individual groups were assessed using one-way ANOVA with Duncan's multiple range test. $\mathrm{P}<0.05$ was considered to indicate a statistically significant difference. SAS version 9.1 (SAS Institute Inc., Cary, NC, USA) was used for statistical analyses.

\section{Results}

Component identification of Pu-erh tea. In an initial LC-MS/MS analysis of the methanol extract of $\mathrm{Pu}$-erh tea, there were 14 important peaks of Pu-erh tea. These peaks demonstrated that the important components of $\mathrm{Pu}$-erh tea were gallic acid (1.70 $\mathrm{min}, \mathrm{m} / \mathrm{z}, 169)$, resorcylic acid (3.43 $\mathrm{min}, \mathrm{m} / \mathrm{z}$ 153), epigallocatechin $(9.10 \mathrm{~min}, \mathrm{~m} / \mathrm{z} 305)$, catechin $(9.30 \mathrm{~min}$, $\mathrm{m} / \mathrm{z}$ 289), caffeine (9.62 $\mathrm{min}, \mathrm{m} / \mathrm{z} .195)$, epicatechin (10.73 min, $\mathrm{m} / \mathrm{z}$ 289), epigallocatechin gallate (10.87 min, $\mathrm{m} / \mathrm{z} 457$ ), epicatechin gallate (12.51 $\mathrm{min}, \mathrm{m} / \mathrm{z} 441)$, quercetin-3-galactoside (12.74 $\mathrm{min}, \mathrm{m} / \mathrm{z}$ 463), kaempferol-3-rutinoside (13.24 min, $\mathrm{m} / \mathrm{z}$ 593), kaempferol-3-glucoside (13.51 $\mathrm{min}, \mathrm{m} / \mathrm{z} 447$ ), quercetin (15.39 $\mathrm{min}, \mathrm{m} / \mathrm{z} 301)$, kaempferol (17.37 $\mathrm{min}, \mathrm{m} / \mathrm{z} 285$ ) and lutein (25.09 $\mathrm{min}, \mathrm{m} / z$ 568) (Fig. 1).

Body weight, diet intake, water intake, stool weight and stool moisture of mice. The weight of mice among the normal, control, bisacodyl and Pu-erh tea 200, 400 and $800 \mathrm{mg} / \mathrm{kg}$ dose groups increased from the first to the sixth day (Fig. 2). Taking activated charcoal induced constipation from the sixth day and the weight of normal group mice increased continually. The weight of the bisacodyl group mice increased less than that in the normal group and the weight of the mice in the control group decreased substantially. The body weight of mice in the $\mathrm{Pu}$-erh tea dose groups also decreased and the weight of the higher concentration dose group mice reduced slowly.

Constipation refers to bowel movements that are infrequent or hard to pass. Therefore, defecation is the most important criterion of constipation. From the first to the sixth day, defecation weight, particle counts of defecation and water content of defecation in each group was not significantly different. 
A

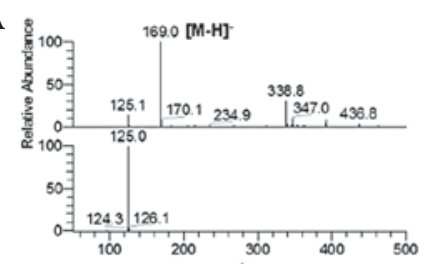

D

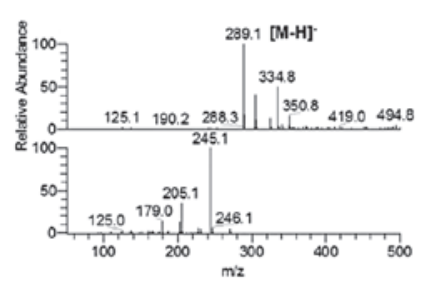

G

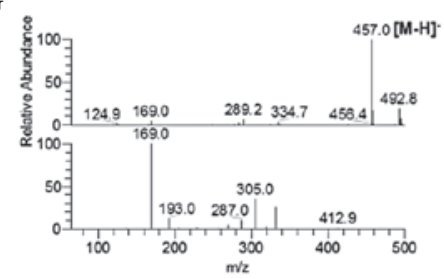

J

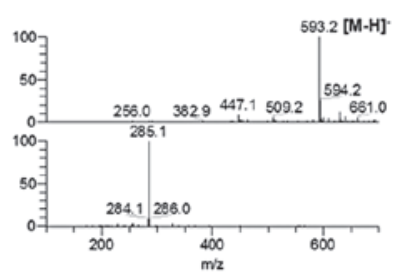

B

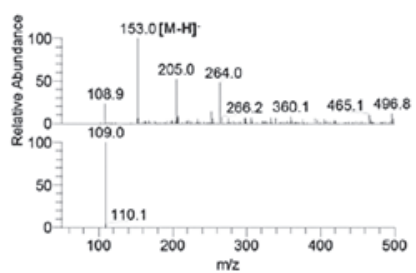

E

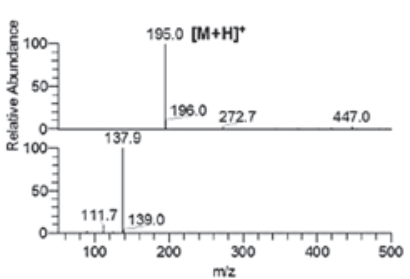

H



K

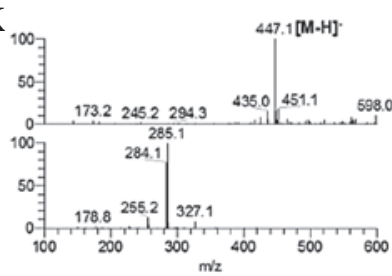

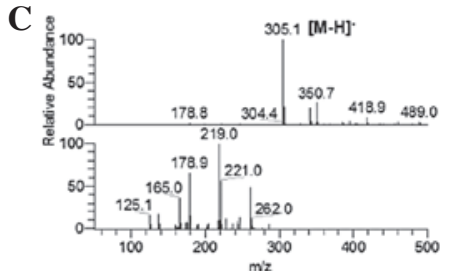

F

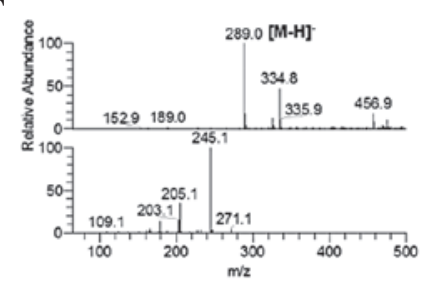

I

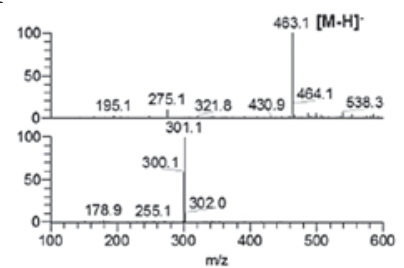

L

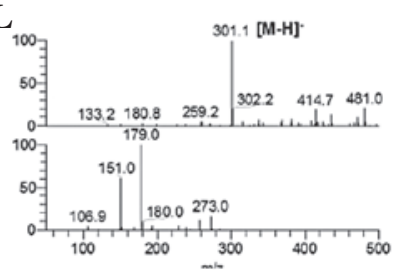

M

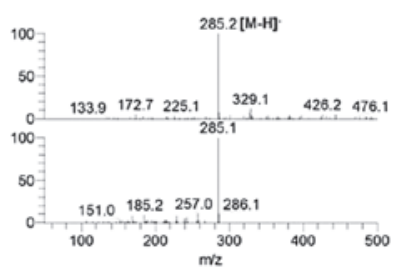

N

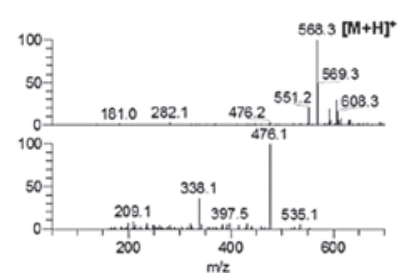

Figure 1. Mass spectra (upper ones of each peak) and MS/MS fragmentation patterns (lower ones of each peak) of 14 important peaks of Pu-erh tea. (A) Gallic acid $\left[\mathrm{m} / \mathrm{z}, 169,(\mathrm{M}-\mathrm{H})^{-}\right]$; (B) resorcylic acid $(\mathrm{m} / \mathrm{z}, 153) ;(\mathrm{C})$ epigallocatechin $\left[\mathrm{m} / \mathrm{z} 305,(\mathrm{M}-\mathrm{H})^{-}\right] ;$(D) catechin $\left(\mathrm{m} / \mathrm{z} 289,(\mathrm{M}-\mathrm{H})^{-}\right] ;(\mathrm{E}) \mathrm{caffeine}\left[\mathrm{m} / \mathrm{z}, 195,(\mathrm{M}+\mathrm{H})^{+}\right]$; (F) epicatechin $\left[\mathrm{m} / \mathrm{z} 269,(\mathrm{M}-\mathrm{H})^{-}\right]$; (G) epigallocatechin gallate $\left[\mathrm{m} / \mathrm{z}, 457,(\mathrm{M}-\mathrm{H})^{-}\right]$; (H) epicatechin gallate $[\mathrm{m} / \mathrm{z}$ 441, (M-H) $]$; (I) quercetin-3-galactoside [m/z 463, (M-H)]; (J) kaempferol-3-rutinoside [m/z 593, (M-H)]; (K) kaempferol-3-glucoside [m/z 447, (M-H)']; (L) quercetin [m/z 301, (M-H)]; (M) kaempferol $(m / z, 285) ;(\mathrm{N})$ lutein $\left[\mathrm{m} / \mathrm{z} 568,(\mathrm{M}+\mathrm{H})^{+}\right]$.

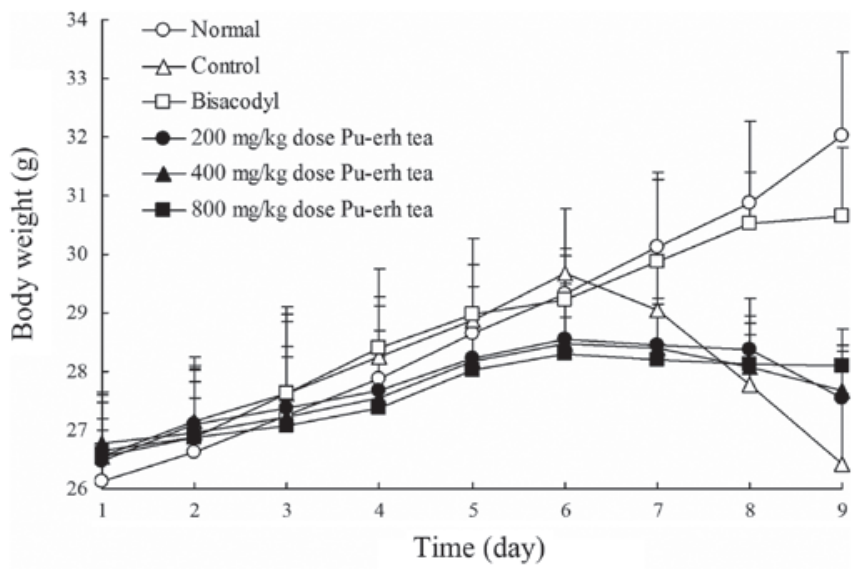

Figure 2. Body weight changes of activated-carbon induced constipation in mice during the experiment. ICR mice ( $\mathrm{n}=20$ in each group) and $100 \mathrm{mg}$ / kg body weight of bisacodyl.
Defecation weight and particle counts of defecation in the bisacodyl group mice were slightly higher than the normal group and the water content of defecations was slightly higher (Table I). Induced constipation, starting from the seventh to the ninth day, decreased defecation weight, particle counts and the water content of defecation. The defecation weight, particle counts and water content of defecation of higher concentration $\mathrm{Pu}$-erh tea and bisacodyl dose mice demonstrated little influence, close to those of the normal mice. Through the observation of the samples treated mice which reduce anorexia, it was determined that $\mathrm{Pu}$-erh tea has a powerful inhibitory effect on constipation, as does bisacodyl.

First black stool defecation time and gastrointestinal transit of mice. As displayed in Fig. 4, the first black stool defecation time of each mice group administered with activated carbon 

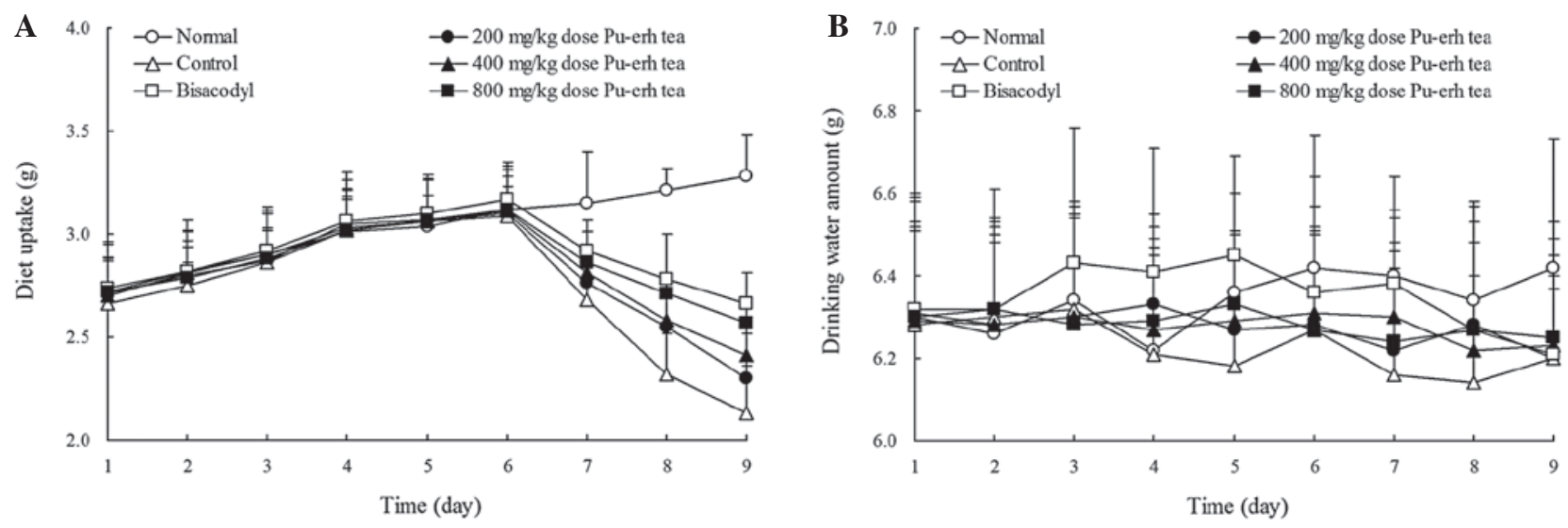

Figure 3. (A) Changes in dietary intake and (B) drinking water amount in activated-carbon induced constipation in mice during the experiment. ICR mice ( $\mathrm{n}=20$ in each group) and $100 \mathrm{mg} / \mathrm{kg}$ body weight of bisacodyl.

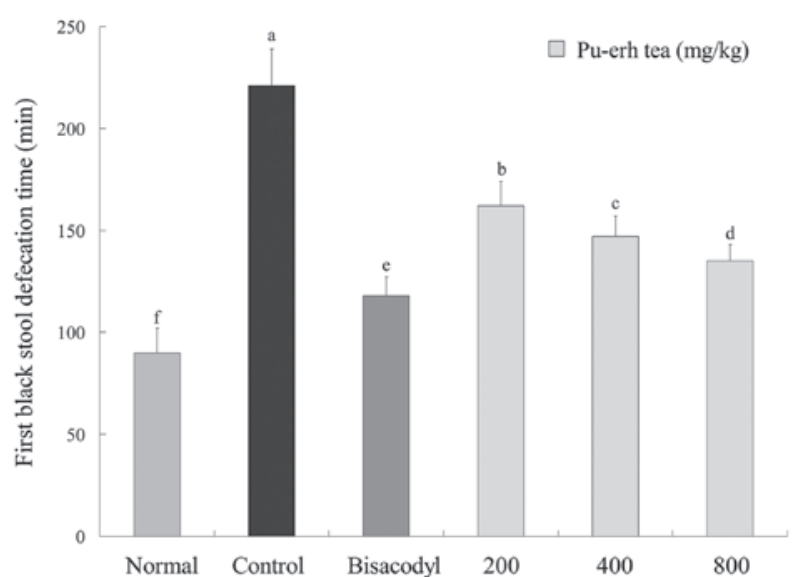

Figure 4. Effects of Pu-erh tea on first black stool defecation time in activated carbon-induced constipation in mice. ICR mice ( $\mathrm{n}=10$ in each group) and $100 \mathrm{mg} / \mathrm{kg}$ body weight of bisacodyl. ${ }^{\mathrm{a}-\mathrm{f}}$ Mean values with different letters over the bars are significantly different $(\mathrm{P}<0.05)$ according to Duncan's multiple range test.

demonstrates the inhibitory effect of the samples on constipation. Defecation time was the shortest $(90 \pm 12 \mathrm{~min})$ in the normal group, with the longest $(221 \pm 18 \mathrm{~min})$ time in the control group. The time for the bisacodyl group was $118 \pm 9$ min, which was only slightly higher than the normal group. Under 200, 400 and $800 \mathrm{mg} / \mathrm{kg}$ dosage concentrations, first black stool defecation times were $162 \pm 12,147 \pm 10$ and $135 \pm 8 \mathrm{~min}$, respectively. According to the defecation time, it is evident that $\mathrm{Pu}$-erh tea had a stronger inhibitory effect on constipation.

The constipation inhibitory effects of samples were determined by gastrointestinal transits. The mice were administered activated carbon $(0.2 \mathrm{ml} /$ mouse, $10 \%$ activated carbon). In the bisacodyl treated group, GI transits were $87.3 \pm 5.2 \%$ which were more than that of the control group (28.9 $\pm 4.6 \%)$ (Fig. 5). At the 200,400 and $800 \mathrm{mg} / \mathrm{kg}$ body weight dose of Pu-erh tea extract, the GI transits were $83.3 \pm 4.1$ and $79.3 \pm 4.1 \%$, respectively. The Pu-erh tea was able to increase the gastrointestinal transit more than the control and higher doses were able to reduce constipation.

MTL, Gas, ET, SS, AchE, SP and VIP levels in serum. The MTL level of normal mice was $170.2 \pm 12.6 \mathrm{pg} / \mathrm{ml}$; whereas that in the activated carbon-induced constipation control mice decreased to $106.2 \pm 9.8 \mathrm{pg} / \mathrm{ml}$ (Fig. 6). The level of MTL in mice fed with bisacodyl was $158.5 \pm 8.7 \mathrm{pg} / \mathrm{ml}$. The levels of MTL in mice treated with 200,400 and $800 \mathrm{mg} / \mathrm{kg}$ of $\mathrm{Pu}$-erh tea were $123.6 \pm 9.2,134.2 \pm 9.5$ and $142.2 \pm 8.1 \mathrm{pg} / \mathrm{ml}$, respectively. The changes of Gas levels of normal, control, $100 \mathrm{mg} / \mathrm{kg}$ dose bisacodyl, 200, 400 and $800 \mathrm{mg} / \mathrm{kg}$ dose mice were $78.1 \pm 4.8,48.9 \pm 2.7,71.4 \pm 3.9,55.3 \pm 4.4,63.4 \pm 3.2$ and $68.1 \pm 3.7$, respectively. At the 200,400 and $800 \mathrm{mg} / \mathrm{kg}$ body weight doses, the levels of ET in the Pu-erh tea groups were $8.1 \pm 0.3,8.6 \pm 0.3$ and $9.4 \pm 0.4 \mathrm{pg} / \mathrm{ml}$ and the normal, control and bisacodyl mice were $12.1 \pm 0.4,7.8 \pm 0.2$ and $11.5 \pm 0.4 \mathrm{pg} /$ $\mathrm{ml}$, respectively. The SS levels of normal and control mice were $35.9 \pm 2.0$ and $60.4 \pm 3.2 \mathrm{pg} / \mathrm{ml}$, the sample dose mice were $39.8 \pm 2.2(100 \mathrm{mg} / \mathrm{kg}$ of bisacodyl), $54.6 \pm 2.7(200 \mathrm{mg} / \mathrm{kg}$ of Pu-erh tea), $48.7 \pm 2.4$ (400 mg/kg of Pu-erh tea) and $42.5 \pm 1.8$ $(800 \mathrm{mg} / \mathrm{kg}$ of Pu-erh tea) $\mathrm{pg} / \mathrm{ml}$, respectively. The AchE, SP and VIP levels of normal mice were $30.1 \pm 1.4,60.3 \pm 3.1$ and $50.1 \pm 2.5 \mathrm{pg} / \mathrm{ml}$, the bisacodyl dose mice were $28.1 \pm 1.3$, $53.2 \pm 2.7$ and $46.4 \pm 1.9 \mathrm{pg} / \mathrm{ml}$, the $200(19.4 \pm 1.2,44.6 \pm 2.4$ and $39.9 \pm 1.4 \mathrm{pg} / \mathrm{ml}), 400(22.3 \pm 1.6,47.8 \pm 1.8$ and $43.5 \pm 1.4 \mathrm{pg} / \mathrm{ml})$ and $800 \mathrm{mg} / \mathrm{kg}(26.4 \pm 1.1,50.9 \pm 1.9$ and $45.1 \pm 0.9 \mathrm{pg} / \mathrm{ml})$ dose $\mathrm{Pu}$-erh tea mice were higher than that in the control mice $(14.0 \pm 1.1,39.1 \pm 2.7$ and $32.3 \pm 0.9 \mathrm{pg} / \mathrm{ml})$.

\section{Discussion}

Pu-erh tea is known as a medicinal tea because of its various health benefits. Long-standing consumers of Pu-erh tea believe this beverage has anti-aging properties and is able to prolong life. Pu-erh tea has been demonstrated to have antifungal, antimicrobial, antioxidant, antimutagenic, antitumor and weight reduction effects (11).

$\mathrm{Pu}$-erh tea contained functional contents of epigallocatechin, catechin, quercetin-3-galactoside, kaempferol-3-rutinoside, kaempferol-3-glucoside, quercetin and kaempferol. These contents may be useful for preventing constipation. Green tea contains epigallocatechin and catechin and may be effective in preventing constipation. There are also numerous other epigallocatechin products for constipation that are manufactured (12). Quercetin-3-galactoside, kaempferol-3-rutinoside, kaempferol-3-glucoside, quercetin 
Table I. Defecation status of mice during the experiment when the mice were treated with activated carbon.

\begin{tabular}{lcccccc}
\hline & & & & \multicolumn{2}{c}{ Pu-erh tea (mg/kg) } \\
\cline { 5 - 7 } Content & Normal & Control & Bisacodyl & 200 & 400 & 800 \\
\hline 1-6 day (dose with samples) & & & & & & \\
Defecation weight (g) & $0.89 \pm 0.12$ & $0.86 \pm 0.08$ & $1.05 \pm 0.10$ & $0.90 \pm 0.08$ & $0.92 \pm 0.07$ & $0.94 \pm 0.05$ \\
Particle counts of defecation & $36 \pm 6$ & $34 \pm 9$ & $48 \pm 4$ & $40 \pm 8$ & $41 \pm 8$ & $43 \pm 9$ \\
Water content of defecation (\%) & $47 \pm 6$ & $48 \pm 3$ & $55 \pm 5$ & $51 \pm 7$ & $51 \pm 5$ & $52 \pm 6$ \\
7-9 day (dose with samples and activated carbon) & & & & & $0.55 \pm 0.06$ \\
Defecation weight (g) & $0.87 \pm 0.06$ & $0.24 \pm 0.03$ & $0.65 \pm 0.10$ & $0.45 \pm 0.05$ & $0.51 \pm 0.06$ & 0.50 \\
Particle counts of defecation & $38 \pm 4$ & $16 \pm 6$ & $42 \pm 3$ & $28 \pm 3$ & $31 \pm 4$ & $35 \pm 3$ \\
Water content of defecation (\%) & $48 \pm 5$ & $13 \pm 2$ & $42 \pm 5$ & $30 \pm 3$ & $33 \pm 4$ & $37 \pm 4$ \\
\hline
\end{tabular}

ICR mice ( $\mathrm{n}=20$ in each group) and $100 \mathrm{mg} / \mathrm{kg}$ body weight of bisacodyl.

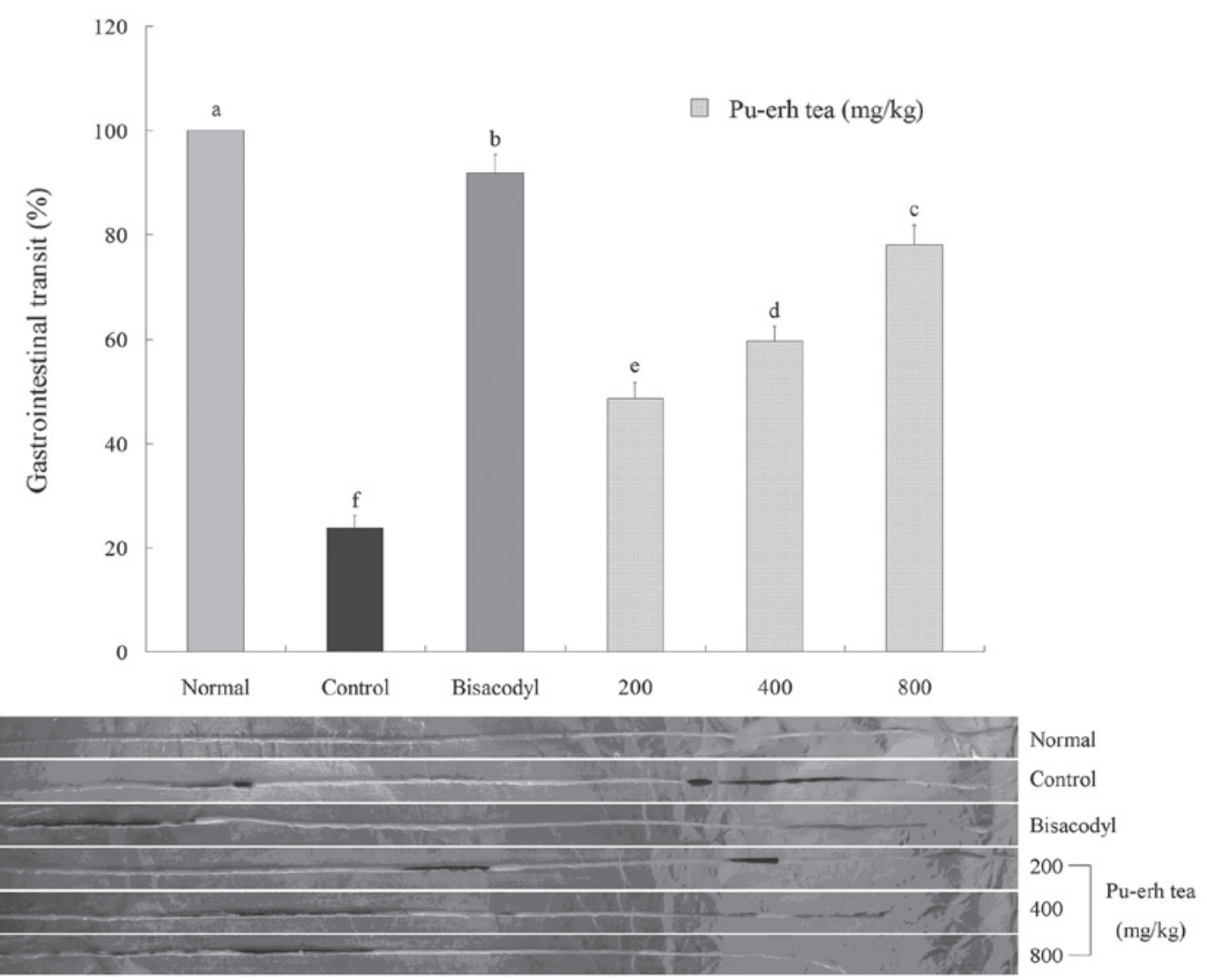

Figure 5. Effects of Pu-erh tea on gastrointestinal transit in activated carbon-induced constipation in mice. $\mathrm{n}=10 \mathrm{ICR}$ mice in each group, $100 \mathrm{mg} / \mathrm{kg}$ body weight of bisacodyl. ${ }^{\mathrm{a}-\mathrm{f}}$ Mean values with different letters over the bars are significantly different $(\mathrm{P}<0.05)$ according to Duncan's multiple range test.

and kaempferol are functional contents that are able to alleviate indigestion, flatulence and constipation (13-15).

Anorexia is an important symptom of constipation (16). Through observing the dietary intake and drinking water amount of mice, we may determine constipation and the inhibitory effect of mice treated with different samples. The definition of constipation includes infrequent bowel movements and difficulty during defecation $(17,18)$.

Constipation most commonly occurs when the stool that forms following food digestion moves too slowly (slow transit) as it passes through the digestive tract. Dehydration, changes in diet and activity and certain drugs are frequently to blame for the slow transit of stool. When stool moves slowly, too much water is absorbed from the stool and it becomes hard and dry (19). Defecation status, dietary intake, drinking water amount, stool defecation time and gastrointestinal transit are important standards for constipation inspection.

The serum levels of MTL, Gas, ET, AchE, SP and VIP in patients with constipation are lower than those in healthy patients and the SS level was higher than the general 



Figure 6. Effect of Pu-erh tea on serum motilin (MTL), gastrin (Gas), endothelin (ET), acetylcholine enzyme (AchE), substance P (SP) and vasoactive intestinal peptide (VIP) levels in activated carbon-induced constipation. ICR mice ( $\mathrm{n}=10$ in each group) and $100 \mathrm{mg} / \mathrm{kg}$ body weight of bisacodyl. ${ }^{\text {a-f }} \mathrm{Mean}$ values with different letters over the bars are significantly different $(\mathrm{P}<0.05)$ according to Duncan's multiple range test.

population (20-22). The main function of MTL is to increase the migrating myoelectric complex component of gastrointestinal motility and stimulate the production of pepsin. It is one of the intestinal hormones responsible for the proper filling and emptying of the gastrointestinal system in response to the intake of food and hunger stimuli (23). Gas is a polypeptide hormone secreted by certain cells of the pyloric glands, which markedly stimulates the secretion of gastric acid and pepsin and weakly stimulates the secretion of pancreatic enzymes and contraction of the gall bladder (24). Gas has effects throughout the gastrointestinal tract. It is able to promote gastrointestinal secretion, increase gastrointestinal movement and at the same time it is able to promote pyloric sphincter relaxation. ET is important in the stability of vascular tension and maintains the basic cardiovascular system. Constipation is able to cause diseases, including intestinal obstruction, or colon cancer and is also able to induce or aggravate cardio-cerebro-vascular diseases in the elderly (25). The somatostatin analogue may stimulate intestinal motor complexes and this agent has been used to treat sclerodermatous pseudo-obstruction. Stool is formed from the non-digestible component of food after water is either absorbed or secreted in the large intestine. Mucous is also produced in the large intestine to provide viscosity. Thin segments of muscle line the intestinal tract and contract and relax in concert to propel the stool forward. Muscle contraction and mucous secretion are regulated by 
acetylcholine (26). Patients with slow transit constipation have abnormal neurotransmitter levels in the muscular layer of their intestinal walls. These abnormalities include a deficiency of SP peptide, which is thought to contribute to peristalsis (27). The disturbances in the normal neural content of VIP in the bowel wall in idiopathic constipation and diverticular disease, may initiate or contribute to the functional changes observed in these disorders (28).

The aim of the present study was to demonstrate that $\mathrm{Pu}$-erh tea has a preventive effect on activated carbon-induced constipation in mice. According to the results, it was demonstrated that $\mathrm{Pu}$-erh tea has significant effects on body weight, dietary intake, drinking water amount and feces status, including defecation weight, particle counts of defecation and water content of defecation in ICR mice. First black stool defecation time was only a little longer than bisacodyl. Gastrointestinal transit was longer than in the control and similar to bisacodyl, and various serum levels, including MTL, Gas, ET, AchE, SP and VIP in Pu-erh tea dose mice were higher than in the control mice, with the SS levels demonstrating an opposite tendency. These results suggest that Pu-erh tea has a significant preventive effect on activated carbon-induced constipation in mice.

\section{Acknowledgements}

This study was supported by the Program for Chongqing Innovative Research Team in University (KJTD201325).

\section{References}

1. Weisburger JH: Tea and health: the underlying mechanisms Proc Soc Exp Biol Med 220: 271-275, 1999.

2. Gong ZQ, Watanabe N, Yagi A, Etoh H, Sakata K, Ina K and Liu QJ: Compositional change of Pu-erh tea during processing. Biosci Biotechnol Biochem 57: 1745-1746, 1993.

3. Duh PD, Yen GC, Yen WJ, Wang BS and Chang LW: Effects of pu-erh tea on oxidative damage and nitric oxide scavenging. J Agric Food Chem 52: 8169-8176, 2004.

4. Ueki A and Otsuka M: Life style risks of Parkinson's disease: Association between decreased water intake and constipation. J Neurol 251: 18-23, 2004.

5. Wexner SD, Beck DE, Baron TH, Fanelli RD, Hyman N, Shen B and Wasco KE: A consensus document on bowel preparation before colonoscopy: prepared by a task force from the American society of colon and rectal surgeons (ASCRS), the American society for gastrointestinal endoscopy (ASGE), and the society of American gastrointestinal and endoscopic surgeons (SAGES). Dis Colon Rectum 49: 792-809, 2006.

6. Farrugia G, Miller SM, Rich A, Liu X, Maines MD, Rae JL and Szurszewski JH: Distribution of heme oxygenase and effects of exogenous carbon monoxide in canine jejunum. Am J Physiol 274: G350-G358, 1998.

7. Farrugia G, Lei S, Lin X, Miller SM, Nath KA, Ferris CD, Levitt $\mathrm{M}$ and Szurszewski JH: A major role for carbon monoxide as an endogenous hyperpolarizing factor in the gastrointestinal tract. Proc Natl Acad Sci USA 100: 8567-8570, 2003.

8. Miller SM, Reed D, Sarr MG, Farrugia G and Szurszewski JH: Haem oxygenase in enteric nervous system of human stomach and jejunum and co-localization with nitric oxide synthase. Neurogastroenterol Motil 13: 121-131, 2001.
9. Xue L, Farrugia G, Miller SM, Ferris CD, Snyder SH and Szurszewski JH: Carbon monoxide and nitric oxide as coneurotransmitters in the enteric nervous system: evidence from genomic deletion of biosynthetic enzymes. Proc Natl Acad Sci USA 97: 1851-1855, 2000.

10. Lee JS, Kim DH, Liu KH, Oh TK and Lee CH: Identification of flavonoids using liquid chromatography with electrospray ionization and ion trap tandem mass spectrometry with an MS/MS library. Rapid Commun Mass Spectrom 19: 3539-3548, 2005.

11. Wu SC, Yen GC, Wang BS, Chiu CK, Yen WJ, Chang LW and Du PD: Antimutagenic and antimicrobial activities of pu-erh tea. LWT-Food Sci Technol 40: 506-512, 2007.

12. Chrubasik C, Maier T, Dawid C, Torda T, Schieber A, Hofmann T and Chrubasik S: An observational study and quantification of the actives in a supplement with Sambucus nigra and Asparagus officinalis used for weight reduction. Phytother Res 22: 913-918, 2008.

13. Ghoneim AI and Eldahshan OA: Anti-apoptotic effects of tamarind leaves against ethanol-induced rat liver injury. J Pharm Pharmacol 64: 430-438, 2012.

14. Lin MC, Lin JH, Chen SK, Cheng YW and Cheng HW: Simultaneous determination of podophyllotoxin, quercetin and kaempferol in podophyllin by liquid chromatography tandem mass spectrometry. J Food Drug Anal 16: 29-40, 2008.

15. Maki KC, Reeves MS, Farmer M, et al: Green tea catechin consumption enhances exercise-induced abdominal fat loss in overweight and obese adults. J Nutr 139: 264-270, 2009.

16. Dolk A, Brodén G, Holmström B, Johansson C and Schultzberg M: Slow transit chronic constipation (Arbuthnot Lane's disease). An immunohistochemical study of neuropeptide-containing nerves in resected specimens from the large bowel. Int $\mathbf{J}$ Colorectal Dis 5: 181-187, 1990

17. Walia R, Mahajan L and Steffen R: Recent advances in chronic constipation. Curr Opin Pediatr 21: 661-666, 2009.

18. Emmanuel AV,Tack J,Quigley EMand Talley NJ:Pharmacological management of constipation. Neurogastroenterol Motil 21: 41-54, 2009.

19. Lubowski DZ, Chen FC, Kennedy ML and King DW: Results of colectomy for severe slow transit constipation. Dis Colon Rectum 39: 23-29, 1996.

20. Sjölund K, Ekman R, Akre F and Lindner P: Motilin in chronic idiopathic constipation. Scand J Gastroenterol 21: 914-918, 1986.

21. El-Salhy M and Norrgård O: Colonic neuroendocrine peptide levels in patients with chronic idiopathic slow transit constipation. Ups J Med Sci 103: 223-230, 1998.

22. Silkoff P, Karmeli F, Goldin E, Ewenson A, Gilon C, Chorev M, Laufer R, Selinger Z and Rachmilewitz D: Effect of substance P on rat gastrointestinal transit. Digest Dis Sci 33: 74-77, 1988.

23. Feighner SD, Tan CP, McKee KK, et al: Receptor for motilin identified in the human gastrointestinal system. Science 284: 2184-2188, 1999.

24. Preston DM, Adrian TE, Christofides ND, Lennard-Jones JE and Bloom SR: Positive correlation between symptoms and circulating motilin, pancreatic polypeptide and gastrin concentrations in functional bowel disorders. Gut 26: 1059-1064, 1985.

25. Soudah HC, Hasler WL and Owyang C: Effect of octreotide on intestinal motility and bacterial overgrowth in scleroderma. N Engl J Med 325: 1461-1467, 1991.

26. Furchgott RF and Zawadzki JV: The obligatory role of endothelial cells in the relaxation of arterial smooth muscle by acetylcholine. Nature 288: 373-376, 1980.

27. Tzavella K, Riepl RL, Klauser AG, Voderholzer WA, Schindlbeck NE and Müller-Lissner SA: Decreased substance $\mathrm{P}$ levels in rectal biopsies from patients with slow transit constipation. Eur J Gastroenterol Hepatol 8: 1207-1211, 1996.

28. Milner P, Crowe R, Kamm MA, Lennard-Jones JE and Burnstock G: Vasoactive intestinal polypeptide levels in sigmoid colon in idiopathic constipation and diverticular disease. Gastroenterology 99: 666-675, 1990. 